Varoujean POGHOSYAN, АРМЯНЕ - СПоДВИжНИКИ

НАПОЛЕОНА : ИСТОРИЯ И МИФЫ [Les Arméniens, compagnons d'armes de Napoléon : histoire et mythes]

\title{
Pierre Barral
}

\section{(2) OpenEdition Journals}

\section{Édition électronique}

URL : https://journals.openedition.org/ahrf/12258

DOI : 10.4000/ahrf.12258

ISSN : 1952-403X

\section{Éditeur :}

Armand Colin, Société des études robespierristes

\section{Édition imprimée}

Date de publication : 1 décembre 2011

Pagination : 185-186

ISSN : 0003-4436

Référence électronique

Pierre Barral, « Varoujean pogнosyan, Армяне - сподвижники Наполеона : история и мифы [Les Arméniens, compagnons d'armes de Napoléon : histoire et mythes] ", Annales historiques de la Révolution française [En ligne], 366 | octobre-décembre 2011, mis en ligne le 14 février 2012, consulté le 01 juillet 2021. URL : http://journals.openedition.org/ahrf/12258 ; DOI : https://doi.org/10.4000/ahrf.12258

Ce document a été généré automatiquement le 1 juillet 2021.

Tous droits réservés 


\title{
Varoujean POGHOSYAN, APMЯHE -
}

\section{СПОДВИЖНИКИ НАПОЛЕОНА : ИСТОРИЯ}

И МИФЫ [Les Arméniens, compagnons

d'armes de Napoléon : histoire et

mythes]

\author{
Pierre Barral
}

\section{RÉFÉRENCE}

Varoujean POGHOSYAN, АРМЯНЕ - СПОДВИЖНИКИ НАПОЛЕОНА : ИСТОРИЯ И МИФЫ [Les

Arméniens, compagnons d'armes de Napoléon : histoire et mythes], Erevan, Edit Print, 2009, 141 p. (Résumé français)

1 Depuis 1990, Varoujean Poghosyan informe régulièrement les lecteurs des AHRF des travaux parus en langue russe sur l'histoire de la Révolution française; ce précieux éclairage extérieur enrichit nos connaissances et nos interprétations. Dans le livre présent, dédié à la mémoire de Victor Daline (1902-1985), avec qui il a travaillé de 1978 à sa mort, il entreprend de faire le point sur la participation de compatriotes arméniens à l'épopée napoléonienne. Si ces personnages insolites ont déjà retenu l'attention des chroniqueurs, l'auteur scrute avec soin les documents, en s'efforçant de démêler les réalités des légendes qui ont prospéré.

Quand il est revenu de son aventure d'Égypte en 1799, Bonaparte a ramené avec lui « le mamelouk Roustam ", guerrier oriental qui apportait une note de prestige et d'exotisme. Ce garde du corps, qui veillait constamment sur lui et dormait à sa porte, a connu la célébrité. Il subsiste de lui un beau portrait, qui serait l'œuvre du baron Gros, et il apparaitt souvent dans les entourages représentés. Stendhal et Balzac évoquent sa personnalité originale, ainsi que Tolstoï dans Guerre et Paix. Surtout, il a été publié en 
1888, et réédité à plusieurs reprises, des Mémoires qui lui sont attribués. Leur authenticité a soulevé une controverse. Un scribe les a sans doute pris sous la dictée et a dû les aménager : la deuxième partie (après 1809) marque une différence de style avec la première. Frédéric Masson et Jean Savant ont affiné le portrait de ce personnage original.

Varoujean Poghosyan tient à souligner les origines de Roustam : il est né à Tiflis, capitale de la Géorgie, mais dans la famille d'un négociant arménien. Très jeune, il est enlevé, réduit en servage et vendu à Constantinople aux agents d'un bey mamelouk d'Égypte, Sala: destin assez courant pour des chrétiens caucasiens au physique vigoureux, incorporés de force dans les armées ottomanes. Et un peu plus tard, le cheikh el Bakri, son nouveau maître, juge habile de l'offrir en cadeau au conquérant français, avec un destrier arabe, à la selle décorée. En France, le mamelouk s'adapte vite, il est placé en vue lors du sacre et il suit l'empereur dans ses campagnes à travers l'Europe. Il est couvert de faveurs et on le marie même à la fille d'une camériste de l'impératrice. Sa silhouette fascine les curieux, jusqu'à faire de lui une cible des pamphlétaires britanniques. Mais les rumeurs qui le mirent en cause dans les morts violentes du général Pichegru et de l'amiral Villeneuve semblent sans fondement. L'auteur relève son attachement à ses racines arméniennes : il se préoccupe du sort de sa famille au pays, il sympathise avec les compatriotes qu'il rencontre, les religieux mekhitaristes de Venise ou les habitants d'un quartier de Moscou.

En 1814 cependant, comme les maréchaux à un autre niveau, il fait défection. Par lassitude, il refuse d'accompagner à l'île d'Elbe le souverain déchu. Devant cet abandon, celui-ci aurait seulement haussé les épaules, mais, au retour des Cent Jours, il ne reprend pas l'ingrat. L'auteur blâme ce comportement et rejette les tentatives de justification présentées par certains historiens arméniens récents. Roustam, surveillé par la police royale, termine sa vie dans le bourg rural de Dourdan. Il aura encore la joie de reprendre son uniforme en 1840 pour assister au triomphal retour des cendres, cinq ans avant sa propre mort.

On ignore souvent que, dès 1798 , Bonaparte a renforcé l'armée d'Orient de corps auxiliaires indigènes et que plus tard la garde impériale compte tout un escadron de mamelouks en turban, tel Ouanis Petro, également présenté ici. Cet autre soldat mamelouk passé dans les rangs français arrive en France en 1801, avec le contingent rapatrié d'Égypte. Combattant valeureux, il est blessé à Austerlitz et reçoit la Légion d'honneur.

6 Il participe à dix campagnes, se distingue en Espagne et affronte encore le feu dans l'ultime bataille de Waterloo. Il n'est pas mort retiré à Marseille, comme il a été écrit par erreur. À partir de documents familiaux, Varoujean Poghosyan établit qu'il est retourné au Karabakh, terre arménienne où il était né, et qu'il y a servi dans l'armée russe, lors de la guerre contre la Perse de 1826 à 1828 , ce qui lui a valu une autre décoration.

7 Une dernière notice est consacrée à une fable infondée, qui attribue une origine arménienne lointaine à Joachim Murat, fils d'un aubergiste du Quercy, beau-frère de Napoléon, qui deviendra maréchal d'Empire puis roi de Naples. Un écrivain imaginatif, Magda Neyman, a développé cette thèse dans un livre de 1899, réédité récemment. Varoujean Poghosyan la réfute avec énergie, en s'appuyant sur les documents généalogiques. Il suppose que l'erreur peut provenir d'une ressemblance de nom avec 
Mourad bey, le meilleur chef des mamelouks égyptiens (qui serait d'ailleurs lui aussi des natifs du Caucase). 